\title{
A randomised, prospective study of 'off-the-shelf' use of toric intraocular lenses for cataract patients with pre-existing corneal astigmatism in the NHS
}

\author{
Nick Stanojcic $\mathbb{D}^{1,2} \cdot$ Harry Roberts $\mathbb{B}^{1,2} \cdot$ Vijay Wagh ${ }^{1} \cdot$ Bruno Zuberbuhler ${ }^{3} \cdot$ David O'Brart $^{1,2}$ \\ Received: 18 August 2019 / Revised: 28 February 2020 / Accepted: 21 April 2020 / Published online: 30 July 2020 \\ (c) The Author(s), under exclusive licence to The Royal College of Ophthalmologists 2020
}

\section{Learning Objectives}

Upon completion of this activity, participants will be able to:

1. Assess the efficacy of off-the-shelf use of 2-diopter cylinder correction toric intraocular lenses in cataract surgery for patients with preoperative corneal astigmatism of $2.00 \mathrm{D}$ or more, based on a prospective randomised study.

2. Evaluate the safety and patient-reported outcomes of off-the-shelf use of 2-diopter cylinder correction toric intraocular lenses in cataract surgery for patients with preoperative corneal astigmatism of $2.00 \mathrm{D}$ or more, based on a prospective randomised study.

3. Determine the potential suitability of off-the-shelf use of toric intraocular lenses for more widespread adoption by the National Health Service or other large public health programs, and other clinical implications of their efficacy and safety, based on a prospective randomised study.

\section{Continuing Medical Education}

In support of improving patient care, this activity has been planned and implemented by Medscape, LLC and Springer Nature. Medscape, LLC is jointly accredited by the Accreditation Council for Continuing Medical Education (ACCME), the Accreditation Council for Pharmacy Education (ACPE), and the American Nurses Credentialing Center (ANCC), to provide continuing education for the healthcare team.

Medscape, LLC designates this Journal-based CME activity for a maximum of 1.00 AMA PRA Category 1 Credit(s). Physicians should claim only the credit commensurate with the extent of their participation in the activity.

All other clinicians completing this activity will be issued a certificate of participation. To participate in this journal CME activity: (1) review the learning objectives and author disclosures; (2) study the education content; (3) take the post-test with a $75 \%$ minimum passing score and complete the evaluation at www.medscape.org/journal/eye; (4) view/print certificate.

\section{Credit hours}

1.0

Release date: July 30, 2020

Expiration date: July 30, 2021

Post-test link: https://medscape.org/eye/posttest929021

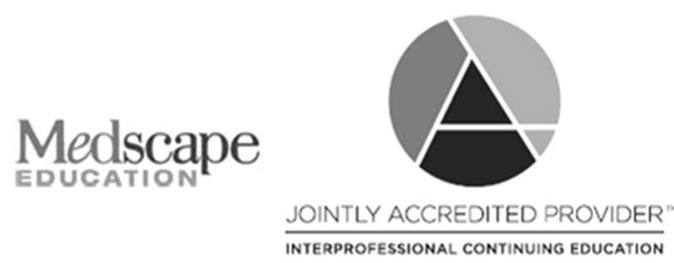

Supplementary information The online version of this article (https:// doi.org/10.1038/s41433-020-0919-8) contains supplementary material, which is available to authorised users.

Nick Stanojcic

nstanojcic@doctors.org.uk

1 Department of Ophthalmology, King's College London Frost Eye Research Unit, Guy's and St Thomas' NHS Foundation Trust, Lambeth Palace Road, London SE1 7EH, UK
King's College, London, UK

Zubimed Augenzentrum, Niederhasli, Switzerland 


\section{Authors/Editors disclosure information}

Sobha Sivaprasad, MD, has disclosed the following relevant financial relationships: served as an advisor or consultant for: Allergan, Inc.; Apellis; Bayer AG; Boehringer Ingelheim Pharmaceuticals, Inc.; Heidelberg Pharma GmbH; Novartis; Oculis; Optos; Oxurion; Roche. Served as a speaker or a member of a speakers bureau for: Allergan, Inc.; Bayer AG; Novartis Pharmaceuticals Corporation; Optos. Received grants for clinical research from: Allergan, Inc.; Bayer AG; Boehringer Ingelheim Pharmaceuticals, Inc.; Novartis Pharmaceuticals Corporation; Optos. Nick Stanojcic, BSc, MCOptom, FRCOphth, has disclosed no relevant financial relationships. Harry Roberts, MSc, FRCOphth, has disclosed the following relevant financial relationships: served as an advisor or consultant for: Alcon UK. Vijay Wagh, FRCOphth, has disclosed no relevant financial relationships. Bruno Zuberbuhler, PhD, FRCOphth, has disclosed no relevant financial relationships. David O'Brart, MD (Res), FRCOphth, FRCS, RefCert(RCOphth), has disclosed the following relevant financial relationships: received grants for clinical research from: Alcopn Inc., Rayner Ltd, Avedro Inc. Owns stock, stock options, or bonds from: Sparca Inc. Employed by a commercial interest: Sparca Inc.

\section{Abstract}

Background/objectives To compare visual and refractive outcomes of monofocal intraocular lenses (IOLs) with limbal relaxing incisions (LRI) with 'off-the-shelf' use of toric IOLs (TIOLs), with a fixed 2-dioptre cylinder (DC) correction, for cataract patients with pre-existing corneal astigmatism in a public-sector setting.

Subjects/methods Seventy-seven patients (77 eyes, first treated eye) with visually significant cataract and pre-operative corneal astigmatism $\geq 2.00$ DC were randomised to receive either 'off-the-shelf' TIOLs, with a fixed 2.00 DC cylinder correction (39 eyes), or monofocal IOLs (38 eyes) with LRIs. The concept of fixing the cylindrical correction was to minimise costs, allow a full TIOL bank to be available and eliminate the need for individual TIOL ordering. Outcome measures were uncorrected distance visual acuity (UDVA), corrected distance visual acuity (CDVA) and refraction. Astigmatic changes were evaluated using the Alpins vector method.

Results Mean UDVA improved from logMAR 0.88 (SD 0.56)[ 20/150] pre-operatively to 0.18 (SD 0.19)[ 20/30] postoperatively in TIOL group, versus 0.82 (SD 0.55)[ 20/130] to 0.27 (SD 0.15)[ 20/40] in monofocal/LRI group $(P=0.02$; 95\% CI: $-0.17,-0.01$ ). Mean CDVA improved from logMAR 0.40 (SD 0.26)[ 20/50] to 0.01 (SD 0.12)[ 20/20] in TIOL group, and 0.41 (SD 0.38)[ 20/40] to 0.06 (SD 0.12)[ 20/25] in LRI group $(P=0.07 ; 95 \%$ CI: $-0.11,0.01)$. Average postoperative refractive cylinder in TIOL group was 1.35 DC (SD 0.84 DC) and in LRI group 1.91 DC (SD 1.07 DC) $(P=0.01$; $95 \%$ CI: $-1,-0.12$ ). Mean difference vector magnitude was 1.92 DC (SD 1.08 DC) in LRI group and 1.37 DC (SD 0.84 DC) in TIOL group $(P=0.02 ; 95 \% \mathrm{CI}: 0.11,0.99)$.

Conclusions TIOLs with a fixed 2.00 DC correction during cataract surgery may improve UDVA, reduce post-operative cylinder and result in a more reliable astigmatic correction compared with monofocal IOLs with LRIs.

\section{Introduction}

Corneal astigmatism is common in patients undergoing cataract surgery [1,2], with more than $40 \%$ of patients undergoing cataract surgery reported to have $>1.00$ dioptre (D) of astigmatism and $10 \%$ have $2.00 \mathrm{D}$ or more [3]. Failing to address this corneal astigmatism at the time of cataract surgery is likely to result in sub-optimal postoperative uncorrected distance visual acuity (UDVA), less spectacle-independence, and increased costs to the patient, all of which in turn has been shown to be associated with reduced quality of life scores [4]. There are several methods available to the cataract surgeon to address the correction of corneal astigmatism at the time surgery, which are either corneal- or intraocular lens (IOL)-based. TIOLs have been found to be a more favourable option than peripheral corneal relaxing incisions (PCRIs), with less risk of overcorrection and irregular astigmatism [5].
Because of the large number of spherical and cylindrical power combinations for TIOLs, they need be ordered in advance with the correct cylinder and spherical power for each patient individually (a customised approach) and thus additional costs will be incurred in terms of administrative time. Indeed, a toric lens that offers a range of cylinders from $+1.00 \mathrm{D}$ to $+6.00 \mathrm{D}$ in $0.50 \mathrm{D}$ increments, and a range of spherical powers from $+6.00 \mathrm{D}$ to $+30.00 \mathrm{D}$ in $0.50 \mathrm{D}$ increments, has a total of 539 different lens combinations and "on-site storage" of such large numbers of lens combinations is usually not possible. Many of those lenses would be expected to pass their expiry date without being used, resulting in significant wastage costs. In addition, the need to manufacture such multiple lens permutations is not without significant associated costs, which are typically passed on to the consumer. Both these added budgetary factors, in addition to the need for increased patient counselling and possible further surgeries 
to re-position toric lenses, make this TIOLs less suitable for high-volume public-sector cataract surgery. Because of such considerations, TIOLs are not routinely offered in the National Health Service (NHS) (Cataract NICE guidelines 2018, available at www.nice.org.uk/guidance/ng77).

An alternative approach to the customised ordering of TIOLs for individual patients would be to hold a limited bank of such lenses e.g., with only 2.00 DC, which would only double the number of a monofocal IOL bank. Given that $\sim 10 \%$ of patients will have $\geq 2.00$ DC but only $1 \%$ of patients will have $>4.00$ DC [3], our approach would offer $99 \%$ of patients with 2.00 to $4.00 \mathrm{D}$ of corneal astigmatism an expected post-operative cylinder of $<2.00 \mathrm{D}$.

The aim of this current study was to evaluate this idea of 'off-the shelf' +2.00 DC TIOLs with a focus on suitability for NHS cataract surgery to allow its more widespread adoption in the public health sector. We performed a randomised prospective study for patients with corneal astigmatism $\geq 2.00 \mathrm{D}$ with subjects randomised to receive either monofocal IOLs with limbal relaxing incisions (LRIs) or TIOLs with the fixed 2.00 DC correction (+2.00 DC).

\section{Materials and methods}

Following ethical and institutional review board approval (reference 11/NW/0428), participants were recruited into this randomised prospective subject-masked study, from the cataract and anterior segment clinics at Guy's and St. Thomas' NHS Foundation Trust, London. The study adhered to tenets of the declaration of Helsinki. Full informed consent was obtained from each participant.

Inclusion criteria included patients with bilateral cataracts and at least 2.00 D corneal astigmatism on Scheimpflug tomography (Pentacam, Oculus Optikgeräte GmbH, Wetzlar, Germany). All patients were over 18 years of age, with visually significant cataract, could understand the rationale and processes of the study and were able to undergo fully informed consent. Patients with amblyopia, corneal scarring, previous intraocular (e.g., corneal, retinal) or extraocular surgery (e.g., squint) or any ocular or neurological condition that would affect their visual outcome were excluded.

Suitable participants once consented, were randomised to cataract surgery and implantation of either an aspheric TIOL (T-Flex 623T; Rayner, Worthing, West Sussex, UK) with a fixed $2.00 \mathrm{D}$ cylindrical correction, or an aspheric monofocal IOL (MIOL; C-Flex 970C; Rayner, Worthing, West Sussex, UK) combined with LRIs.

Randomisation was performed using computer-generated random number tables (Excel, Microsoft Corporation, WA, USA). First treated eye was the study eye. Surgical team were not masked to the treatment. Biometry was performed with
IOL master 500 (Carl Zeiss Meditec, AG, Germany). In cases of dense cataracts, axial length was measured with an A-scan (Carl Zeiss Meditec AG, Germany). SRK/T formula was used for calculation of IOL power except in cases where axial length was $<21 \mathrm{~mm}$ when Hoffer Q formula was used.

\section{Surgical technique}

Participants' eyes were marked pre-operatively at the slitlamp under topical anaesthesia using both an insulin-type needle and a marking pen. Limbal markings were placed at 0 and $180^{\circ}$. All surgeries were performed by consultant surgeons or senior anterior segment fellows (NS, HR, VW, BZ and DOB) under local anaesthesia (topical or subTenon) using 'Infinity' platform (Alcon Inc., USA) and a $2.4 \mathrm{~mm}$ on-axis incision. After cataract extraction IOL was injected into the capsular bag under viscoelastic (Provisc, Alcon Inc., USA). A Mendez-style ring was used to mark the eye intra-operatively and align the IOL axis or to place the LRIs. Sodium fluorescein (2\% Minims, Bausch \& Lomb, USA) was used intra-operatively to highlight the epithelial markings placed pre-operatively.

\section{Toric group}

TIOL power and axis orientation calculations were carried out using 'Raytrace Premium IOL calculator' (Rayner Intraocular Lenses Ltd, UK). A subjective refraction or auto-refraction values were used in these TIOL calculations. The IOL alignment with the planned meridian was checked with the Mendez-style ring at the end of the surgery.

\section{Limbal relaxing incisions (LRI) group}

LRIs were calculated using the 'LRIcalculator' (Abbott Medical Optics Inc., USA; available at https://www.lrica lculator.com) and the 'Donnenfeld' nomogram was chosen for all calculations. Paired LRIs incisions with on-axis surgery were used to provide maximum effect. When surgery was performed off-axis, surgeon's SIA was used to modify the LRI. A 600 micron diamond guarded blade was used to place LRIs at the beginning of surgery.

\section{Follow-up and data collection}

Post-operatively, all patients received chloramphenicol eye drops four times per day for 2 weeks and dexamethasone $0.1 \%$ eye drops four times per day for 4 weeks. Patients who received TIOL were reviewed at 1 week (to check rotational stability of the TIOL) and then at 4 weeks. Patients who received the MIOLs and LRIs were reviewed at 4 weeks. Technicians, nurses and optometrists were 
masked to the treatment each participant received. All patients were always dilated with tropicamide $1 \%$ and phenylephrine $2.5 \%$ and the degree scale on the vertical arm of the slit-lamp was used to measure the IOL axis.

Primary outcome measures were post-operative $\log M A R$ visual acuities: UDVA and corrected distance visual acuity (CDVA) assessed by an Early Treatment Diabetic Retinopathy Study backlit chart at $4 \mathrm{~m}$ (Precision Vision, IL, USA) at 1 month. Refractive outcomes were measured with subjective refraction at 1 month and astigmatic changes (including vectoral analyses) based on pre-operative keratometric measurements as assessed by Pentacam tomography (Oculus Optikgeräte GmbH, Wetzlar, Germany) and post-operative subjective refraction measurement. Preoperative and post-operative keratometric astigmatism changes in the two groups were also analysed. Vectoral analyses were evaluated using the Alpins vector method [6] and calculating the following parameters: target induced astigmatism (TIA), surgically induced astigmatism (SIA), difference vector (DV), magnitude of error (ME), correction index (CI), index of success (IS), coefficient of adjustment (CA), torque, flattening and flattening index (FI).

Secondary outcome measures were TIOL rotational stability data and safety data for both groups. Following an amendment to the protocol during the study, patientreported outcome measures (PROMs) were studied using Cat-PROM5 [7, 8] questionnaire as well as EuroQOL EQ$5 \mathrm{D}$ quality of life questionnaire with visual analogue score (VAS) (https://euroqol.org).

\section{Statistical analysis}

Data organisation and descriptive statistics were managed using Excel 2013 software (Microsoft Corporation, WA, USA). Alpins vector analysis was performed with VekTrAK software (available at http://www.assort.com).

Continuous data were reported as means \pm standard deviation (SD) when data was normally distributed. Parametric data were analysed with the student $t$ test using a two-sided $P$ value of $\alpha=0.05$. This was an exploratory study and hence formal power calculations were not undertaken. The Rasch-calibrated Cat-PROM5 scores were analysed using the Excel macros provided by the developer [7, 8]. The EQ-5D index scores were analysed using the VAS method calibrated for the UK. Safety data were compared using the Fisher's exact test.

\section{Results}

Seventy-seven eyes from 77 patients were enroled between January 2015 and November 2018. Thirty-nine patients received TIOLs and thirty-eight patients received MIOL with LRI. Baseline patient demographics of the two treatment groups are shown in Table 1.

Following surgery, mean UDVA improved from logMAR 0.88 (SD 0.56)[ 20/150] pre-operatively to 0.18 (SD 0.19) [ 20/30] post-operatively in the TIOL group, versus 0.82 (SD 0.55)[ 20/130] to 0.27 (SD 0.15)[ 20/40] in the LRI group $(P=0.02 ; 95 \% \mathrm{CI}-0.17,-0.01)$ (Table 2 and Fig. 1). Mean CDVA improved from logMAR 0.40 (SD 0.26) [20/50] to 0.01 (SD 0.12)[ 20/20] in the TIOL group, and 0.41 (SD 0.38)[ 20/40] to 0.06 (SD 0.12)[ 20/25] in the LRI group $(P=0.07 ; 95 \% \mathrm{CI}-0.11,0.01)$ (Table 2 and Fig. 1).

Mean post-operative refractive cylinder in the TIOL group was $1.35 \mathrm{DC}$ (SD $0.84 \mathrm{DC}$ ) and in the LRI group $1.91 \mathrm{DC}$ (SD 1.07 DC) $(P=0.01 ; 95 \% \mathrm{CI}-1,-0.12)$ (Table 2 and Fig. 1). Mean post-operative spherical equivalent subjective refraction in the TIOL group was $-0.48 \mathrm{D}(\mathrm{SD} 0.49 \mathrm{D})$ and in the LRI group $-0.53 \mathrm{D}$ (SD $0.71)(P=0.72 ; 95 \% \mathrm{CI}-0.23,0.33)$ (Table 2 and Fig. 1$)$. Mean magnitude of the TIA was 2.88 DC (SD 0.80 DC) in the TIOL group (Table 2 and Fig. 2) and 2.87 DC (SD 0.78 DC) in the LRI group $(P=0.96 ; 95 \% \mathrm{CI}-0.37,0.35)$ (Table 2 and Fig. 2). Mean magnitude of the SIA vector was 2.67 DC (SD 1.28 DC) in the TIOL group (Table 2 and Fig. 2) and 2.35 DC (SD 1.79 DC) in the LRI group ( $P=$ $0.37 ; 95 \% \mathrm{CI}-1.03,0.39$ ) (Table 2 and Fig. 2). The mean DV was 1.37 DC (SD 0.84 DC) in the TIOL group and 1.92 DC (SD 1.08 DC) in the LRI group $(P=0.02 ; 95 \%$ CI 0.11 , 0.99) (Table 2). The mean CI was 0.98 (SD 0.54) in the TIOL group and 0.88 (SD 0.63) in the LRI group $(P=0.46$; $95 \%$ CI $-0.37,0.17$ ) (Table 2).

The mean ME was -0.18 DC (SD $1.40 \mathrm{DC}$ ) in the TIOL group and $-0.42 \mathrm{DC}$ (SD 1.91 DC) in the LRI group $(P=$ $0.53 ; 95 \%$ CI $-1,0.52$ ) (Table 2).

Keratometric astigmatism was reduced post-operatively in both groups, but more so in the LRI group (Table 3). However, the difference in reduction between the two groups was not statistically significant $(P=0.25 ; 95 \% \mathrm{CI}$ $-0.19,0.73)$.

\section{Patient-reported outcome measures (PROMs)}

EQ-5D-3L index score showed improvement in both groups and the difference in mean change was not statistically significant $(P=0.47 ; 95 \%$ CI $-0.05,0.1)$ (Table 2). CatPROM5 score showed improvement in self-reported visual function in both groups and the mean change was statistically significantly different between the two groups $(P=$ $0.04 ; 95 \%$ CI $0.28,8.4$ ) (Table 2). The mean change in VAS score was not significantly different in the two groups $(P=0.56 ; 95 \%$ CI $-7.24,13.06)$ (Table 2). 
Table 1 Baseline patient demographics of the two treatment groups.

\begin{tabular}{llll}
\hline Parameter & $\begin{array}{l}\text { Toric IOL group } \\
\text { mean } \pm \text { SD }\end{array}$ & $\begin{array}{l}\text { Monofocal }+ \text { LRI } \\
\text { group mean } \pm \text { SD }\end{array}$ & $\begin{array}{l}P \text { value }^{\mathrm{a}}(95 \% \text { confidence } \\
\text { interval }^{2}\end{array}$ \\
\hline $\begin{array}{l}\text { Gender (M/F) } \\
\text { Age (years) }\end{array}$ & $16 / 23$ & $17 / 21$ & N/A \\
$\begin{array}{l}\text { Corneal astigmatism } \\
\text { dioptres [D]) }\end{array}$ & $2.89 \pm 0.5 \pm 15.1$ & $70.3 \pm 14.7$ & $0.82(-7.57,5.97)$ \\
$\begin{array}{l}\text { Refractive cylinder (D) } \\
\text { Pre-op UDVA (logMAR) }\end{array}$ & $2.80 \pm 1.33$ & $2.87 \pm 0.78$ & $0.96(-0.35,0.37)$ \\
$\begin{array}{l}\text { Pre-op CDVA (logMAR) } \\
\text { Cat-PROM5 Rasch- }\end{array}$ & $0.40 \pm 0.26$ & $2.96 \pm 1.39$ & $0.61(-0.78,0.46)$ \\
calibrated score & $0.92 \pm 2.37^{\mathrm{b}}$ & $0.82 \pm 0.55$ & $0.64(-0.19,0.31)$ \\
$\begin{array}{l}\text { EQ-5D-3L index score } \\
\text { EQ-5D visual }\end{array}$ & $0.90 \pm 0.13^{\mathrm{b}}$ & $0.41 \pm 0.38$ & $0.89(-0.16,0.14)$ \\
analogue scale & $74.5 \pm 18.84^{\mathrm{b}}$ & $80.2 \pm 14.08^{\mathrm{c}}$ & $0.48(-3.12,1.52)$ \\
\hline
\end{tabular}

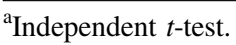

${ }^{\mathrm{b}} n=12$.

${ }^{\mathrm{c}} n=11$.

Table 2 Summary post-operative results including visual and refractive outcomes, patient-reported outcome measures and vectoral analyses.

\begin{tabular}{|c|c|c|c|}
\hline Parameter & Toric IOL group mean $\pm \mathrm{SD}$ & Monofocal + LRI group mean \pm SD & $P$ value $^{\mathrm{a}}(95 \%$ confidence interval) \\
\hline UDVA (logMAR) & $0.18 \pm 0.19$ & $0.27 \pm 0.15$ & $0.02(-0.17,-0.01)$ \\
\hline CDVA (logMAR) & $0.01 \pm 0.12$ & $0.06 \pm 0.12$ & $0.07(-0.11,0.01)$ \\
\hline Refractive cylinder (D) & $1.35 \pm 0.84$ & $1.91 \pm 1.07$ & $0.01(-1,-0.12)$ \\
\hline Spherical equivalent (D) & $-0.48 \pm 0.49$ & $-0.53 \pm 0.71$ & $0.72(-0.23,0.33)$ \\
\hline Keratometric cylinder (D) & $0.81 \pm 2.90$ & $0.78 \pm 2.87$ & $0.96(-1.28,1.34)$ \\
\hline $\begin{array}{l}\text { Change in Cat-PROM5 Rasch- } \\
\text { calibrated score }\end{array}$ & $-2.72 \pm 5.39^{b}$ & $-7.06 \pm 3.75^{\mathrm{c}}$ & $0.04(0.28,8.4)$ \\
\hline Change in EQ-5D-3L index score & $0.03 \pm 0.09^{\mathrm{b}}$ & $0.005 \pm 0.07^{\mathrm{c}}$ & $0.47(-0.05,0.1)$ \\
\hline $\begin{array}{l}\text { Change in EQ-5D visual } \\
\text { analogue scale }\end{array}$ & $4 \pm 9.70^{b}$ & $1.09 \pm 13.55^{\mathrm{c}}$ & $0.56(-7.24,13.06)$ \\
\hline $\begin{array}{l}\text { Magnitude of target-induced } \\
\text { astigmatism (D) }\end{array}$ & $2.88 \pm 0.80(2,5.41)$ & $2.87 \pm 0.78(2,4.70)$ & $0.96(-0.37,0.35)$ \\
\hline $\begin{array}{l}\text { Magnitude of surgically induced } \\
\text { astigmatism (D) }\end{array}$ & $2.67 \pm 1.28(0.74,6.12)$ & $2.35 \pm 1.79(0.19,7.07)$ & $0.37(-1.03,0.39)$ \\
\hline Difference vector magnitude (D) & $1.37 \pm 0.84(0.25,3.65)$ & $1.92 \pm 1.08(0.25,5)$ & $0.02(0.11,0.99)$ \\
\hline Magnitude of error (D) & $-0.18 \pm 1.40(-2.63,2.84)$ & $-0.42 \pm 1.91(-3.75,3.95)$ & $0.53(-1,0.52)$ \\
\hline Angle of error (AE) (degrees) & $-0.72 \pm 14.86(-35,63)$ & $-2.29 \pm 16.96(-50,34)$ & $0.67(-5.66,8.8)$ \\
\hline Index of success (IS) & $0.47 \pm 0.26(0.11,1.22)$ & $0.65 \pm 0.29(0.12,1.30)$ & $0.005(-0.31,-0.06)$ \\
\hline Coefficient of adjustment (CA) & $1.32 \pm 0.69(0.54,3.25)$ & $2.08 \pm 2.05(0.44,11.87)$ & $0.03(-1.45,-0.07)$ \\
\hline Torque (D) & $-0.12 \pm 0.66(-1.93,0.91)$ & $0.09 \pm 0.70(-1.65,1.81)$ & $0.18(-0.52,0.1)$ \\
\hline Flattening (D) & $2.52 \pm 1.42(-0.56,6.11)$ & $2.14 \pm 1.92(-0.18,7.06)$ & $0.33(-0.39,1.15)$ \\
\hline Flattening index $(\mathrm{FI})$ & $0.88 \pm 0.47(-0.19,1.86)$ & $0.77 \pm 0.64(-0.04,2.30)$ & $0.39(-0.14,0.36)$ \\
\hline Correction index $(\mathrm{CI})$ & $0.98 \pm 0.54(0.31,2.80)$ & $0.88 \pm 0.63(0.08,2.30)$ & $0.46(-0.37,0.17)$ \\
\hline
\end{tabular}

$D$ dioptres.

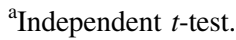

${ }^{\mathrm{b}} n=12$.

${ }^{\mathrm{c}} n=11$.

Statistically significant values are in bold. 
A

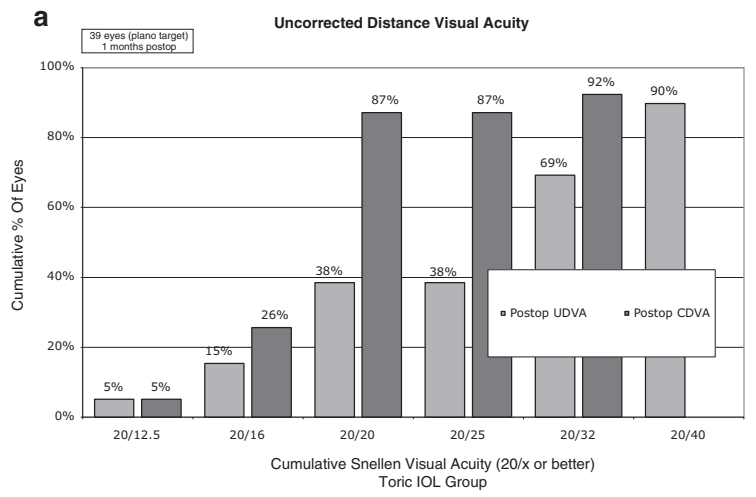

c

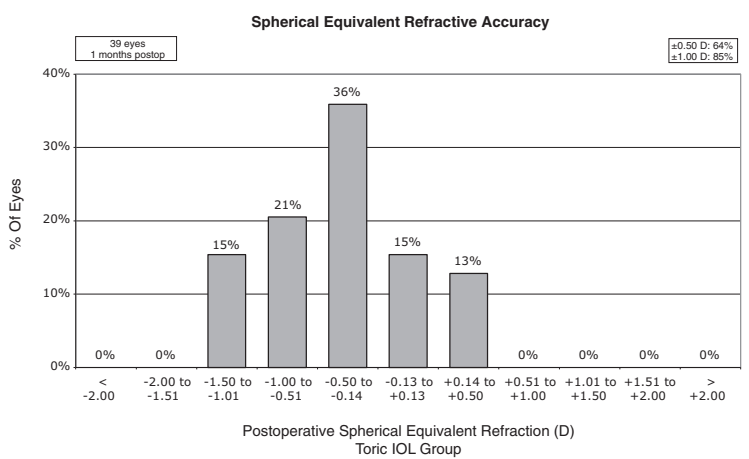

B

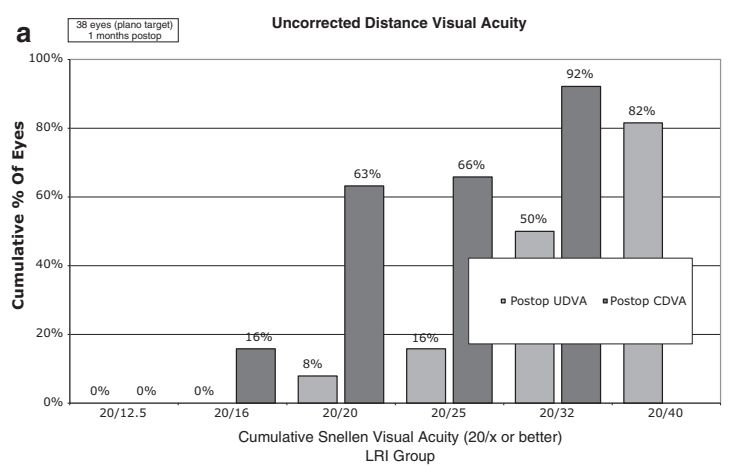

c

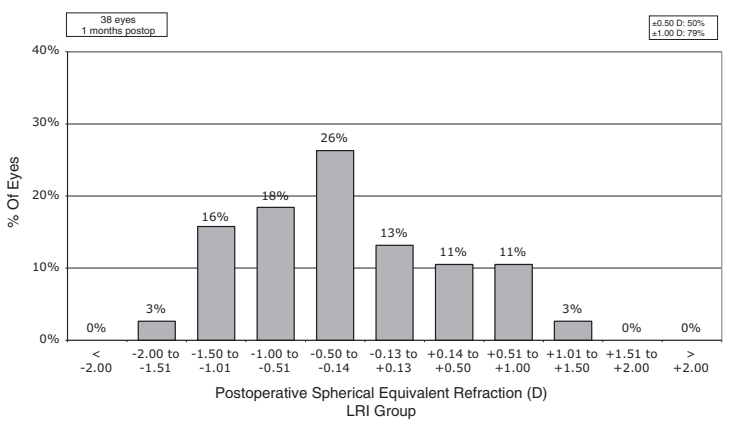

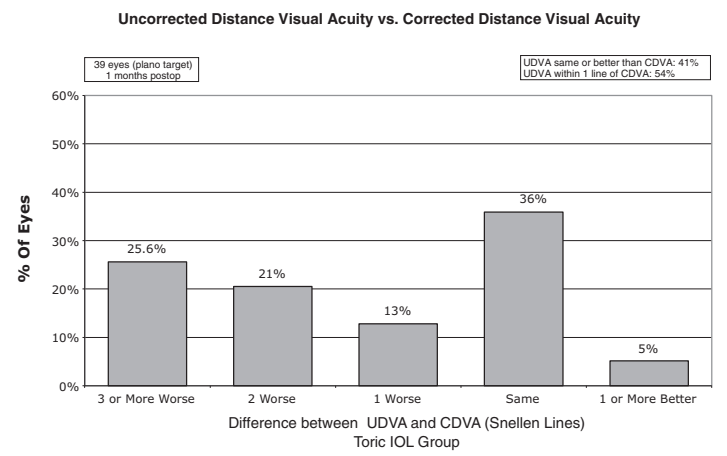

d

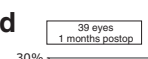

Refractive Cylinder

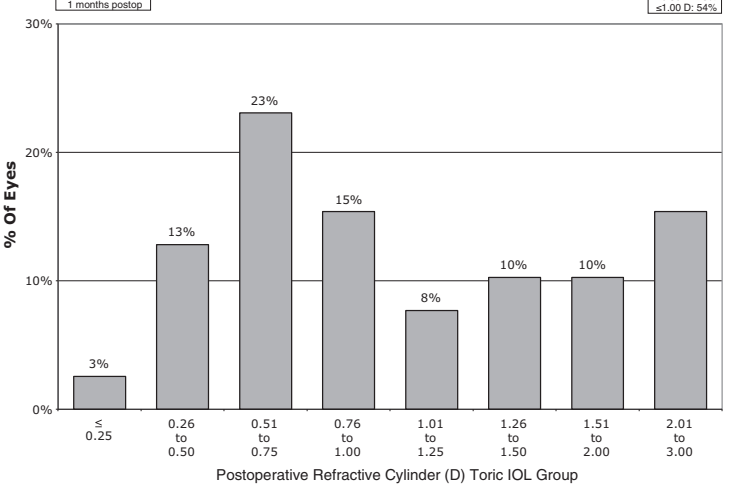

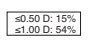

b Uncorrected Distance Visual Acuity vs. Corrected Distance Visual Acuity
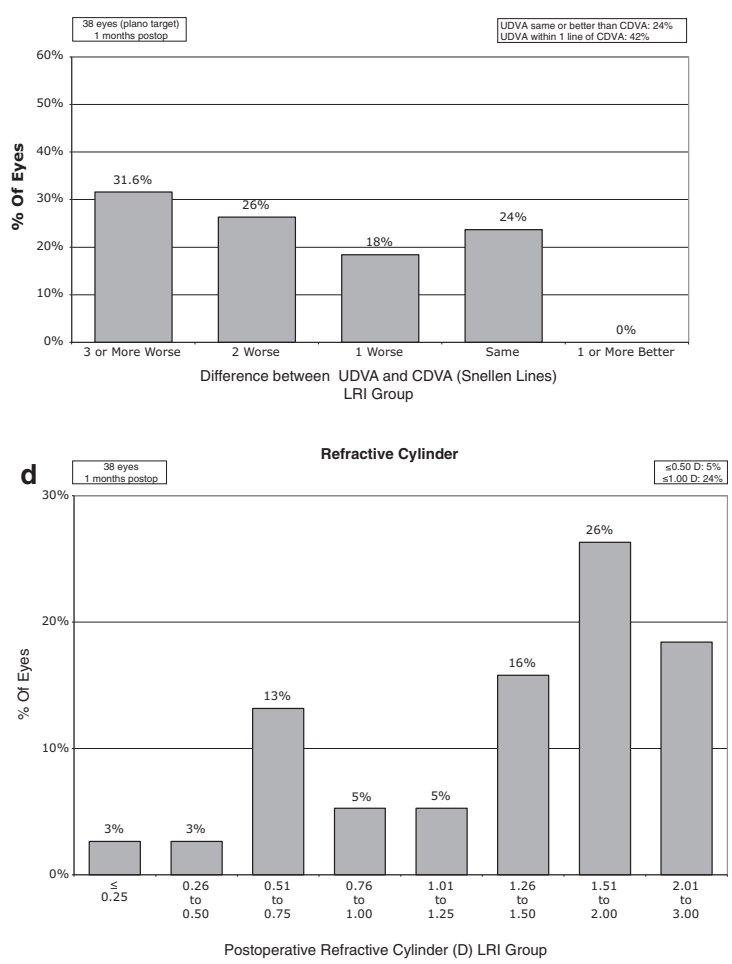

Fig. 1 Refractive outcomes in the toric IOL group (A) and the monofocal + LRI group (B): pre-operative and post-operative UDVA and CDVA (logMAR) (a), difference between UDVA and CDVA (Snellen lines) (b), spherical equivalent subjective refraction (c) and residual refractive cylinder (d). 
a

TIA vs SIA (Toric group)

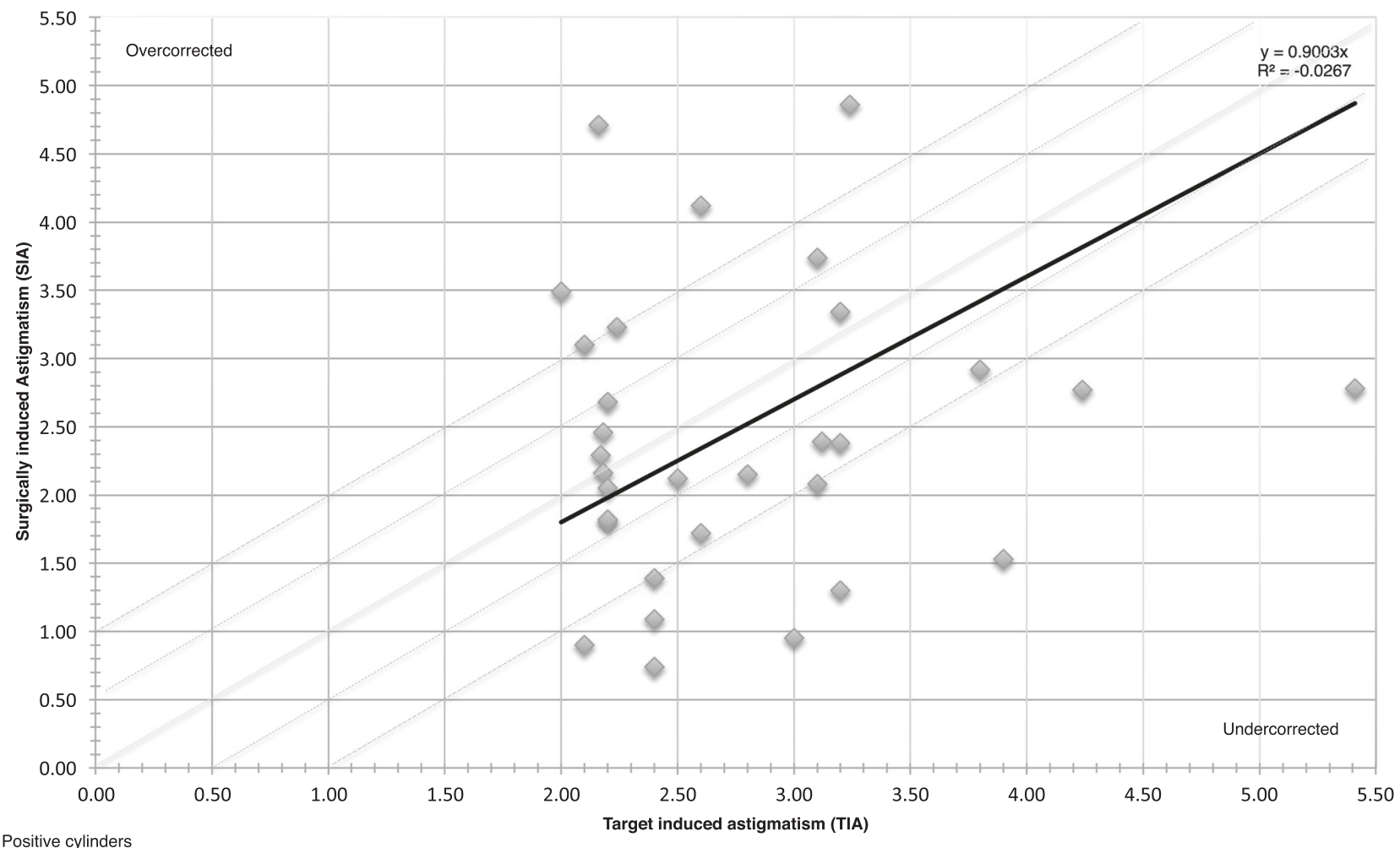

b

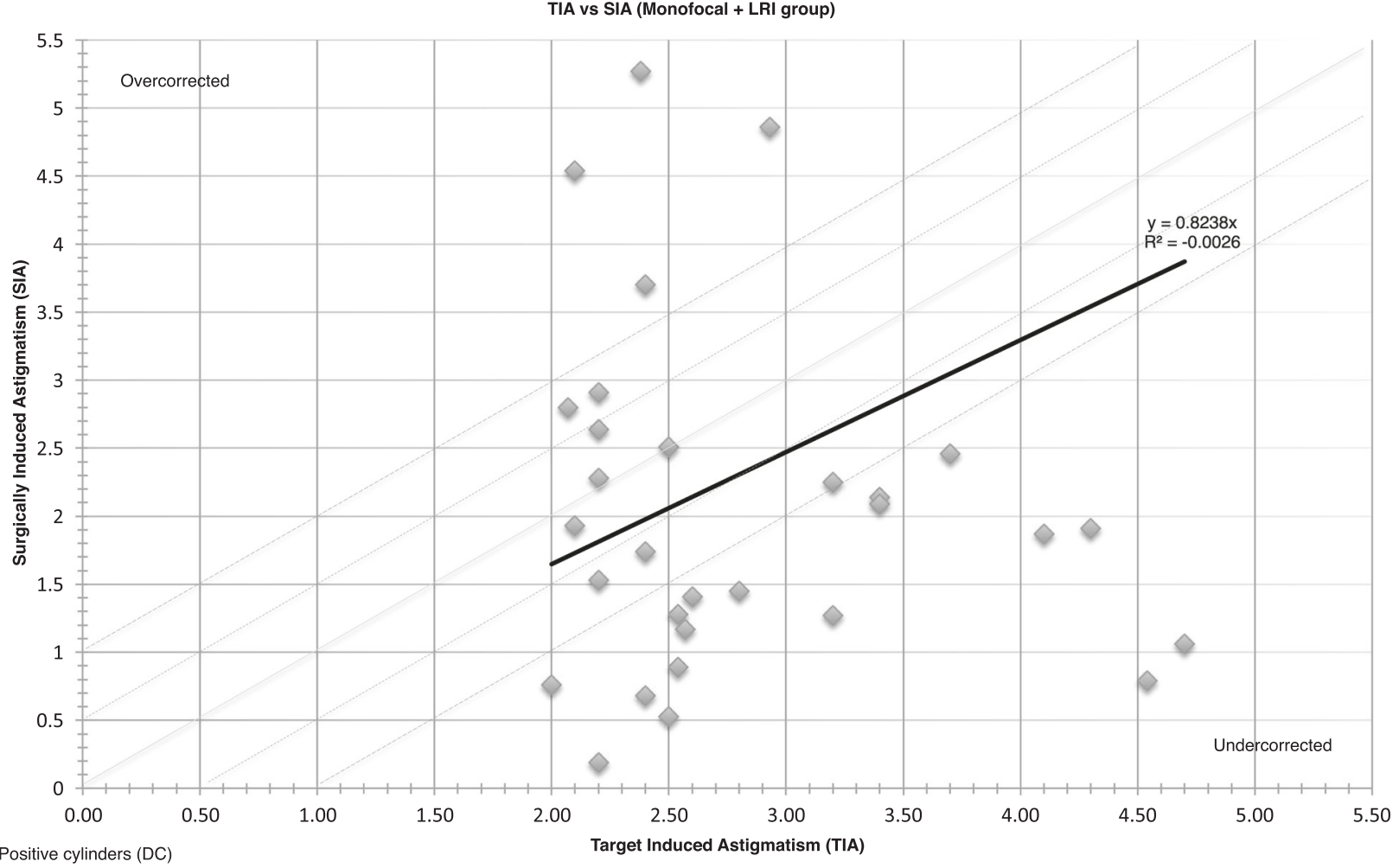

Fig. 2 Target induced astigmatism (TIA) versus surgically induced astigmatism (SIA) (Dioptres) in the toric toric IOL group (a) and the monofocal + LRI group (b). 
Table 3 Keratometric and refractive cylinder change (pre-op vs. post-op) in the toric IOL and LRI groups.

\begin{tabular}{|c|c|c|c|}
\hline & Pre-op mean $\pm \mathrm{SD}($ range $)$ & Post-op mean \pm SD (range) & $P$ value $^{\mathrm{a}}(95 \%$ confidence interval) \\
\hline \multicolumn{4}{|l|}{ Keratometric cylinder (D) } \\
\hline Toric IOL group & $2.88 \pm 0.80(2,5.41)$ & $2.43 \pm 1.05(0.40,5.10)$ & $<0.001(0.24,0.77)$ \\
\hline Monofocal + LRI group & $2.87 \pm 0.78(2,4.70)$ & $2.16 \pm 0.98(0.60,4.10)$ & $<0.001(0.48,0.94)$ \\
\hline$P$ value $^{\mathrm{b}}$ (95\% confidence interval) & $0.96(-0.35,0.37)$ & $0.25(-0.19,0.73)$ & \\
\hline \multicolumn{4}{|l|}{ Refractive cylinder (D) } \\
\hline Toric IOL group & $2.80 \pm 1.33(0.25,6)$ & $1.35 \pm 0.84(0.25,3.75)$ & $<0.001(-1.94,-1.03)$ \\
\hline Monofocal + LRI group & $2.96 \pm 1.39(0.5,6.25)$ & $1.91 \pm 1.07(0.25,5)$ & $<0.001(-1.36,-0.64)$ \\
\hline$P$ value $^{\mathrm{b}}(95 \%$ confidence interval) & $0.61(-0.78,0.46)$ & $0.01(-1,-0.12)$ & \\
\hline
\end{tabular}

${ }^{\mathrm{a}}$ Paired $t$-test.

${ }^{\mathrm{b}}$ Independent $t$-test.

Statistically significant values are in bold.

\section{Axis of TIOL alignment}

The mean difference between the intended and final axis at 4 weeks was $2.39^{\circ} \pm 5.74$. Ninety percent of TIOLs were within $5^{\circ}$ of their intended axis at 1 month. A single TIOL (3\%) had rotated by $41^{\circ}$ and was repositioned at 1 week.

\section{Intra-operative complications}

Complications were only encountered in the TIOL group. Two patients $(2 / 39 ; 5.1 \%)$ required TIOL exchange at the time of surgery due to broken haptics, which was believed to have happened during injection of the IOL. However, this level of intra-operative complications did not reach statistical significance between the groups $(P=0.49)$.

\section{Post-operative complications}

Three patients $(8 \%)$ in the TIOL group developed cystoid macular oedema (CMO) with none in the LRI group $(P=$ 0.24). All were successfully treated (two with topical medications and one required 'Ozurdex' [Allergan, NJ, USA] implant in addition to topical treatment). Mild posterior capsule opacification developed in one patient $(3 \%)$ in the TIOL group. The patient did not experience any symptoms and did not require $\mathrm{Nd}: \mathrm{YAG}$ capsulotomy.

\section{Discussion}

Because of the high volume of cataract surgery undertaken in the NHS and current financial cost restraints, there is a need for studies to investigate strategies to optimise patient outcomes while minimising any cost implications. The aim of this current study was to evaluate a simplified strategy for the use of a lens bank of TIOLs, with a focus on suitability and simplicity of procedure for public-sector (NHS) cataract surgery.

Patients who undergo bilateral customised TIOL implantation have been found to achieve superior spectacle freedom, residual refractive cylinder and distance UDVA compared with patients with bilateral spherical IOLs [9]. Even in the presence of low amounts of corneal astigmatism $(<1.75 \mathrm{D})$, refractive and visual improvements have been shown to be enhanced with TIOLs compared with spherical IOLs [10].

The available scientific literature has mixed result: PCRIs have been shown to have comparable visual outcomes to TIOLs [11-14], whilst other studies have found TIOLs to be more efficacious [15, 16]. A recent systematic review and meta-analysis found that TIOLs provided better UDVA, greater spectacle independence and lower amounts of residual astigmatism than non-toric IOLs even when relaxing incisions were used [17]. However, given current financial constraints, because of associated additional time and costs with the use of TIOLs, current guidelines do not recommend their routine use in the NHS.

In this present study, with 2.00 DC TIOLs implanted in patients with $2.00 \mathrm{D}$ or more of corneal astigmatism, undercorrection in many subjects was inevitable. This is especially so as the effective power of such $2.00 \mathrm{DC}$ TIOL is $<2.00 \mathrm{DC}$ at the corneal plane. However, the original purpose of the study was not to fully correct all patients' astigmatic error but develop a simplified process by which TIOLs could be introduced into the public sector as an 'offthe-shelf' solution and reduce patients' dependence on spectacles. Given such an under-correction, it is difficult to fully compare our TIOL outcomes with other published research with more targeted outcomes. Interestingly, our TIOL group was overall less under-corrected $(\mathrm{CI}=0.98 \pm$ $0.54)$ than LRI group $(\mathrm{CI}=0.88 \pm 0.63)$, but this was not statistically significant $(P=0.46)$. Correction of astigmatism was more successful in the TIOL group (IS $=0.47 \pm$ 
$0.27)$ than in the LRI group $(0.65 \pm 0.29)(P=0.005)$. The statistically significant improvement in the DV in the TIOL group $(P=0.02)$ also suggests that TIOLs were more effective in our cohort than LRIs, despite overall undercorrection. In addition, mean post-operative refractive cylinder was statistically significantly lower in the TIOL group than in the LRI group (Table 3). It should be noted, however, that some reduction in corneal astigmatism in our TIOL group was also induced using on-axis incisions, which achieved statistically significant corneal F (Table 3).

Despite our patients not receiving customised TIOLs, 34 patients $(34 / 38$ or $90 \%)$ still achieved UDVA of 0.3 $\log$ MAR $(6 / 12$ or 20/40) or better. These results are similar those of Gayton and Seabolt [18] who reported UDVA of $6 / 12$ or better in $81 \%$ of patients at 2-month follow-up using an AcrySof TIOL (SN60AT, Alcon Inc., USA) and by Poll et al. [19] who reported $87 \%$ patients achieving an UDVA of 6/12 or better at 1 month also using the AcrySof SN60AT TIOL. Likewise, Stewart and McAlister [20] in a small series of 14 eyes documented UDVA of 6/12 or better at 1 month in $93 \%$ of patients implanted with a Rayner TIOL (573T and 623T; Rayner, Worthing, West Sussex, UK).

Concerning the residual refractive cylinder, reflecting the under-correction with our fixed 2.00 DC correction at the lens plane, our results were less than others' using a more targeted approach. Poll et al. [19] documented that $88 \%$ of patients with TIOLs had $\leq 1.00 \mathrm{D}$ of residual refractive astigmatism at 1-month follow-up, compared with only $56 \%$ of cases in our TIOL group. Similarly, Hirnschall et al. [16] found that $96 \%$ of their patients had $\leq 1.00 \mathrm{D}$ of residual refractive astigmatism, using the Rayner T-flex TIOLs (573T and 623T). Unsurprisingly, in our study only $15 \%$ of patients ended up with $\leq 0.50 \mathrm{D}$ of residual refractive astigmatism, which is lower than that reported by Hirnschall et al. [16] (52\%) and Poll et al. [19] (77\%). It should be noted, however, that in the study by Hirnschall et al. [16] the inclusion criteria were corneal astigmatism between $1.00 \mathrm{D}$ and $2.50 \mathrm{D}$ and their measured pre-op corneal astigmatism was $1.70 \pm 0.42 \mathrm{D}$ (mean $\pm \mathrm{SD}$ ), which is much lower compared with our toric group who had a mean pre-operative corneal astigmatism of $2.88 \pm 0.80 \mathrm{D}$ (range 2, 5.41). Clearly, the refractive results of 'off-the-shelf' 2.00 DC TIOLs will be less efficacious than bespoke TIOL selection, but at the advantage of reduced cost and administrative time.

Despite using established nomograms in our study, the residual refractive astigmatism in our patients receiving LRIs was higher than that reported in the literature. We achieved $\leq 0.50 \mathrm{D}$ and $<1.00 \mathrm{D}$ residual astigmatism in $5 \%$ and $24 \%$ of patients, respectively, compared with $20 \%$ and $44 \%$ reported by Roberts et al. [21] in their manual LRI group, $40 \%$ and $84 \%$ documented by Hirnschall et al. [16] and $42 \%$ and $84 \%$ reported by Tityal et al. [12]. These differences may be explained by the fact that some researchers used different nomograms [17] or that our LRI group had a large proportion of patients with high corneal astigmatism. The mean pre-operative corneal astigmatism in our LRI group was $2.87 \pm 0.78 \mathrm{D}$ compared with $1.57 \pm$ $0.44 \mathrm{D}$ in the study by Hirnschall et al. [16], $1.50 \pm 0.46 \mathrm{D}$ in the study by Roberts et al. [21] and $2.18 \pm 0.59 \mathrm{D}$ in the study by Tityal et al. [12].

Both our treatment groups were similar in terms of mean magnitude of TIA and SIA vectors. Both groups were under-corrected but the LRI group more so and the ME in the TIOL group was close to zero. This finding is similar to that of Lam et al. [13] who found their ME was close to zero in the TIOL group and negative in the LRI group. However, the mean magnitude of DV and the residual refractive cylindrical error in the TIOL group was statistically significantly lower than in the LRI group suggesting that a fixed $2.00 \mathrm{D}$ TIOL is a more reliable way of reducing corneal astigmatism than simply using LRIs. This was also reflected in an improved UDVA in the TIOL group (Table 2 and Fig. 1).

Our toric axis accuracy alignment results compare favourably with other studies that evaluated the alignment accuracy with the same IOL platform. Our mean difference between intended and final axis at 4 weeks was only $2.39^{\circ}$ \pm 5.74 and $90 \%$ of TIOLs were within $5^{\circ}$ of their intended axis at 1 month. Entabi et al. [22], who also used Rayner T-flex 623T TIOL documented that all their patients were within $\pm 15^{\circ}$ of the intended axes, and $91 \%$ were within $\pm 10^{\circ}$ at 4 months. Similarly, Stewart and McAlister [20], found in their group of Rayner TIOL (573T and 623T; nonkeratoplasty arm) that mean rotation was $5.54 \pm 4.65^{\circ}$ (range $1.0^{\circ}, 16.0^{\circ}$ ) at 1 month. Similarly, Lam et al. [13] found TIOL misalignment in three eyes (3/31) of their TIOL group with a mean group misalignment of $7.67\left(\mathrm{SD} 4.04^{\circ}\right)$.

We only experienced intra-operative and post-operative complications in the TIOL group (IOL haptic damage and CMO). However, due to their limited occurrence and small sample sizes these outcomes were not statistically significant. Interestingly, Holland et al. [23] also found that CMO developed in $2.3 \%$ (6/256 eyes) of eyes in their cohort implanted with TIOLs (AcrySof Toric, Alcon Inc., USA) and in $0.8 \%$ (2/261 eyes) in eyes with a spherical control IOL (AcrySof, Alcon Inc., USA). Whether or not such differences are due to increased surgical manipulation or just chance remains undetermined. Overall our CMO rates were safe, compared with the results published in the PREMED study [24].

All PROMs showed improvement post-operatively. The only statistically significant difference between the two groups was a greater improvement in Cat-PROM5 score in the LRI group (Table 2). It is possible that the patients in the LRI group noticed more improvement in their vision 
compared with the TIOL group as their pre-operative CatPROM5 score was worse despite having similar visual outcomes (Table 1), but this may also be a type 1 statistical error. It must be stressed that the PROMs were introduced during the study and these results do not consider all participants. However, PROMs using this set of validated questionnaires have not, to our knowledge, been previously used for evaluation of patients undergoing cataract surgery with fixed-power TIOLs or LRIs.

We did not follow our patients longer than 1 month to investigate the stability of our LRIs, which may diminish with time $[15,16]$. However, a recent study [11] found no statistically significant difference in residual astigmatism over 12 months or regression of astigmatic correction. Moreover, in the same study UDVA at 1 month and 12 months was most closely associated in both the TIOL and the PCRI groups [11].

However, despite these limitations, this study appears to show that keeping a lens bank of standardised +2.00 DC TIOLs with an 'off-the-shelf' approach for patients with more than $2.00 \mathrm{D}$ of corneal astigmatism has the potential to improve patients' post-operative vision significantly, when compared with the use of MIOLs with LRIs, which is the normal standard of care in the UK public sector. Such simplified use of TIOLs has the potential to provide astigmatic cataract patients with better vision, greater spectacle independence, better living quality and cheaper costs for spectacles (lower cumulative financial burden) [25] and the potential to be universally implemented into public-sector high-volume cataract surgery.

\section{Summary}

\section{What was known before}

- Both LRIs and toric IOLs implants are effective in reducing pre-existing corneal astigmatism in cataract patients.

- LRIs and toric IOLs have previously been compared head to head using customised toric IOLs.

\section{What this study adds}

- Off-the-shelf toric IOLs with a fixed 2.00 D cylinder have not previously been compared with LRIs for correcting pre-existing corneal astigmatism in cataract patients.

- PROMs using a combination of Cat-PROM5 and EQ5D validated questionnaires have not previously been used for evaluation of patients undergoing cataract surgery with fixed-power TIOLs or LRIs.

- 'Off-the-shelf' use of toric IOLs with a fixed 2.00 D cylinder correction during cataract surgery may improve
UDVA, reduce post-operative cylinder to a greater extent and provide a more reliable way of reducing corneal astigmatism compared with monofocal IOLs combined with LRIs.

- This simplified strategy for 'off-the-shelf' use of TIOLs has the potential to provide astigmatic cataract patients with better unaided vision and greater spectacle independence.

- This approach also has the potential to be universally implemented into public-sector high-volume cataract surgery such as NHS.

Funding This study was supported by a non-commercial grant from Rayner Ltd, UK. The sponsor or funding organisation had no role in the design or conduct of this research.

\section{Compliance with ethical standards}

Conflict of interest Professor O'Brart has held non-commercial grants from Alcon Inc., USA, Rayner Ltd, UK and Avedro Inc, USA. The other authors declare that they have no conflict of interest.

Ethics approval Ethical approval was granted by North West-Greater Manchester Central Research Ethics Committee (reference 11/NW/ 0428).

Publisher's note Springer Nature remains neutral with regard to jurisdictional claims in published maps and institutional affiliations.

\section{References}

1. Ferrer-Blasco T, Montés-Micó R, Peixoto-de-Matos SC, GonzálezMéijome JM, Cerviño A. Prevalence of corneal astigmatism before cataract surgery. J Cataract Refract Surg. 2009;35:70-5.

2. Hoffmann PC, Hütz WW. Analysis of biometry and prevalence data for corneal astigmatism in 23,239 eyes. J Cataract Refract Surg. 2010;36:1479-85.

3. Khan MI, Muhtaseb M. Prevalence of corneal astigmatism in patients having routine cataract surgery at a teaching hospital in the United Kingdom. J Cataract Refract Surg. 2011;37:1751-55.

4. Tahhan N, Papas E, Fricke TR, Frick KR, Holden BA. Utility and uncorrected refractive error. Ophthalmology. 2013;120:1736-44.

5. Poll JT, Wang L, Koch DD, Weikert MP. Correction of astigmatism during cataract surgery: toric intraocular lens compared to peripheral corneal relaxing incisions. J Refract Surg. 2011;27: 165-71.

6. Alpins N. Astigmatism analysis by the Alpins method. J Cataract Refract Surg. 2001;27:31-49.

7. Sparrow JM, Grzeda MT, Frost NA, Johnston RL, et al. CatPROM5: a brief psychometrically robust self- report questionnaire instrument for cataract surgery. Eye. 2018;32:796-805.

8. Sparrow JM, Grzeda MT, Frost NA, Johnston RL, et al. Cataract surgery patient-reported outcome measures: a head-to-head comparison of the psychometric performance and patient acceptability of the Cat-PROM5 and Catquest-9SF self-report questionnaires. Eye. 2018:32:788-95.

9. Lane SS, Ernest P, Miller KM, Hileman KS, et al. Comparison of clinical and patient-reported outcomes with bilateral AcrySof toric or spherical control intraocular lenses. J Refract Surg. 2009;25:899-901. 
10. Statham M, Apel A, Stephensen D. Comparison of the AcrySof SA60 spherical intraocular lens and the AcrySof Toric SN60T3 intraocular lens outcomes in patients with low amounts of corneal astigmatism. Clin Exp Ophthalmol. 2009;37:775-9.

11. Nanavaty MA, Bedi KK, Ali S, Holmes M, Rajak S. Toric intraocular lenses versus peripheral corneal relaxing incisions for astigmatism between 0.75 and 2.5 diopters during cataract surgery. Am J Ophthalmol. 2017;180:165-77.

12. Titiyal JS, Khatik M, Sharma N, Vatsa Sehra S, et al. Toric intraocular lens implantation versus astigmatic keratotomy to correct astigmatism during phacoemulsification. J Cataract Refract Surg. 2014;40:741-7.

13. Lam DKT, Chow VWS, Ye C, Ng PK, et al. Comparative evaluation of aspheric toric intraocular lens implantation and limbal relaxing incisions in eyes with cataracts and $\leq 3$ dioptres of astigmatism. Br J Ophthalmol. 2016;100:258-62.

14. Mendicute J, Irigoyen C, Ruiz M, Illarramendi I, et al. Toric intraocular lens versus opposite clear corneal incisions to correct astigmatism in eyes having cataract surgery. J Cataract Refract Surg. 2009;35:451-8.

15. Mingo-Botín D, Muñoz-Negrete FJ, Kim HRW, Morcillo-Laiz R, et al. Comparison of toric intraocular lenses and peripheral corneal relaxing incisions to treat astigmatism during cataract surgery. J Cataract Refract Surg. 2010;36:1700-8.

16. Hirnschall N, Gangwani V, Crnej A, Koshy J, et al. Correction of moderate corneal astigmatism during cataract surgery: Toric intraocular lens versus peripheral corneal relaxing incisions. J Cataract Refract Surg. 2014;40:354-61.

17. Kessell L, Andersen J, Tendel B, Erngaard, et al. Toric intraocular lenses in the correction of astigmatism during cataract surgery. Ophthalmology. 2016;123:275-86.
18. Gayton JL, Seabolt RA. Clinical outcomes of complex and uncomplicated cataractous eyes after lens replacement with the AcrySof toric IOL. J Refract Surg. 2011;27:56-62.

19. Poll JT, Wang L, Koch DD, Weikert MP. Correction of astigmatism during cataract surgery: toric intraocular lens compared to peripheral corneal relaxing incisions. J Refract Surg. 2011;27:165-71.

20. Stewart CM, McAlister JC. Comparison of grafted and nongrafted patients with corneal astigmatism undergoing cataract extraction with a toric intraocular lens implant. Clin Exp Ophthalmol. 2010;38:747-57.

21. Roberts H, Wagh VK, Archer T, Sullivan D, O'Brart DPS. Refractive outcomes after limbal relaxing incision or femtosecond laser assisted astigmatic keratotomy in the management of corneal astigmatism at the time of cataract surgery. J Cataract Refract Surg. 2018;44:955-63.

22. Entabi M, Harman F, Lee N, Bloom PA. Injectable 1piece hydrophilic acrylic toric intraocular lens for cataract surgery: efficacy and stability. J Cataract Refract Surg. 2011;37: 235-40.

23. Holland E, Lane S, Horn JD, Ernest P, Arleo R, Miller KM. The AcrySof toric intraocular lens in subjects with cataracts and corneal astigmatism: a randomized, subject-masked, parallel-group, 1-year study. Ophthalmology. 2010;117:2104-11.

24. Wielders LHP, Schouten JSAG, Winkens B, et al. European multicenter trial of the prevention of cystoid macular edema after cataract surgery in nondiabetics: ESCRS PREMED study report 1. J Cataract Refract Surg. 2018;44:429-39.

25. Laurendeau C, Lafuma A, Berdeaux G. Modelling lifetime cost consequences of toric compared with standard IOLs in cataract surgery of astigmatic patients in four European countries. J Med Econ. 2009;12:230-7. 